\title{
Narrativas de la posmodernidad. Del sentimiento como forma a la imagen melodramática
}

\section{Postmodern Narratives. From feeling as a form to image as a melodrama}

\author{
Héctor Eduardo Robledo Mejía y Lirba Mayela Cano Alarcón
}

Universidad Autónoma de Querétaro y Universidad de Celaya

chacsol@gmail.com

\section{Resumen}

El presente trabajo constituye una breve travesía que va de la posmodernidad (definida por la paradoja) al melodrama, con la intención de dar cuenta de cómo se estructuran las narrativas cinematográficas en torno a formas-sentimientos como el dolor y su representación;
narrativas que a la vez son metáfora de la cultura contemporánea que se encuentra trastocada por la irrupción de lo femenino. Tratar a la posmodernidad, lo femenino y el melodrama como formas que juegan de manera que cada una contiene a las otras.

Palabras clave: posmodernidad; forma-sentimiento; lo femenino; melodrama

\section{Abstract}

This paper constitutes a short crossing from postmodernity (defined by paradoxes) to melodrama. The aim is to account for the structure of cinematographic narratives, which develops through forms-feelings as pain and its representation. At the same time these narratives are also a metaphor of contemporary culture affected by the emergence of the feminine. The aim of the paper is to treat postmodernity, the feminine and melodrama as forms, each of them containing the others.

Keywords: Postmodernity; form-feeling; the femenine; melodrama

\section{Paradójicas formas de la posmodernidad: de la palabra al}

\section{sentimiento}

La posmodernidad puede definirse como la fascinación de descubrir que la realidad es más blanda de lo que parecía (Fernández Christlieb, 2005, p.70). Lo posmoderno consiste en decir lo que no se debe mencionar, en que lo de afuera incluya lo de adentro: la revelación y muerte de los metarrelatos. Es la revoltura de fondos y de formas: la fundación de nuevas ficciones dentro de las cuales enmarcar la realidad. La posmodernidad es develar que vivimos en un relato que ha sido contado por alguien concreto, que no es artificio de la naturaleza. Consiste no sólo en saber que lo siniestro es aquello que posibilita y delimita lo bello (Trías, 1985), sino que lo siniestro puede ser bello en sí mismo como relato alternativo de la realidad. La posmodernidad es la posibilidad de pensar que la realidad no está dada de 
antemano ni es homogénea, que es una "construcción social", pero que incluso la idea de construcción social puede ser cuestionada.

Que la realidad sea una construcción social significa que es concebida en el espacio de la intersubjetivdad a través del encuentro de discursos, donde el lenguaje sería la sustancia, la materia viva a través de la cual cobra sentido la realidad (Gergen, 1991). El problema de esta concepción radica en que implica un modelo lógico de pensamiento. La metáfora de construcción quiere decir que un ladrillo va sobre otro, que hay unos cimientos sobre un suelo previamente preparado. Una palabra después de otra daría origen al discurso que permite que haya cosas verdaderas.

Según esta perspectiva discursiva, llamémosle aquí, los sentimientos (emociones, afectos) siguen igualmente patrones lingüísticos, en que el amor consistiría en repetir los diálogos románticos de las películas de Hollywood o las telenovelas para conseguir los efectos deseados, y los científicos pueden ponerse de acuerdo en que se trata de una no muy compleja reacción química. Es decir, que esta idea fervientemente posmoderna de la realidad como construcción social, discursiva, lingüística, no deja de ser moderna, esto es, que apela a la racionalidad de la realidad y la vida. Aparentemente la posmodernidad se traiciona y se hace autogol, pero ya se verá que su signo es el de la paradoja. Sin embargo, esos seres humanos de a pie que creemos que somos, en múltiples ocasiones constatamos que la realidad (y quienes viven en ella) no es así, que está más bien cargada de una entusiasta irracionalidad cuya mejor metáfora no es la palabra, sino la imagen.

Sin ánimo de hacer una cartografía de la posmodernidad, resulta comprensible que a los teóricos europeos y de sociedades ilustradas y muy democráticas, les suene tanto la idea de construcción discursiva: están históricamente acostumbrados a la charla de café, el simposio de universidad y a los acuerdos políticos en el parlamento. Pero hay otras latitudes, i. e. Latinoamérica, donde esa idea no cuadra del todo, pues aunque cuentan con espacios estereotípicos de intercambio de subjetividades como el lavadero o la cantina, la realidad más que explicarse y construirse parece que irrumpe, aparece ya cuajada, abrupta, salvaje, estética, ilógica: radicalmente posmoderna, melodramática, insulsamente afectiva.

Desde ese punto de vista cualquier listado y definición de afectos, sentimientos o emociones siempre fracasaría. Aquí más bien la afectividad sería esa parte de la realidad que es innombrable (Fernández Christlieb, 1999), o sea que lo que se siente no se puede decir y lo que se dice no es lo que se siente. Cuando habla de sentimientos la gente no se refiere a sus sentimientos sino a las palabras con que intenta definirlos, porque el lenguaje en realidad nunca dice nada, lo que intenta es poner límites para que aparezca el sentido (Merleau-Ponty, 1951). Los discursivistas hasta aquí estarían de acuerdo: el lenguaje es la traza de los sentidos colectivos, y los sentidos que aparezcan dependerán en parte de las "destrezas lingüísticas" de los hablantes; el problema es que nunca podemos estar del todo seguros que aquello que yo siento y que nombro, por ejemplo, pereza, sea la misma pereza que tú sientes por el hecho de usar las mismas palabras y las mismas destrezas lingüísticas, lo cual no quiere decir que no estemos sintiendo una profunda y pesada pereza, realidad que a quien la siente le parecerá indiscutible en el sentido extenso del término: digan lo que quieran, la pereza puede resultar aplastante.

Por tanto, una aproximación científica al fenómeno de la afectividad o de los sentimientos se antoja complicada, ya que su "naturaleza ilógica" nunca se corresponderá con los discursos que se hagan de ella. Además de que una aproximación científica a los sentimientos resulta sospechosa, pues se trataría 
de poner en orden aquello que vivimos como radicalmente contingente (Marquard, 1986), y que quizá por eso es lo que realmente nos importa. Entonces, ¿de qué manera podemos aproximarnos a una comprensión de la afectividad y de la posmodernidad? Si lo que se siente no es lo que la gente dice que siente (lo que se dicen son palabras) ¿hay posibilidad de indagar sobre los sentimientos?

Quizá del modo que tiene más sentido abordar los afectos es considerar a estos como formas: hacer una aproximación estética. Eso sí, con la advertencia de las paradojas que siempre nos tiene reservadas la posmodernidad: desde una perspectiva estética el discurso es una forma (Merleau-Ponty, 1951), y desde una perspectiva discursiva la forma es un discurso (Fernández Christlieb, 2004). Lo dicho, la realidad siempre tiene más de una salida.

Una forma es una entidad a la que no le falta nada, por lo que no hay formas incompletas. A pesar de ello la forma se mantiene ambigua e inasible y sus contornos no son todos del mismo material, por lo menos en el caso de los afectos o estados de ánimo, como el mal humor, cuyos límites

pueden estar dados en temperatura, en presión atmosférica, en gravedad, en color, en cosas, en estados orgánicos, en recuerdos, en luz, en edad, en ideas, en ruido. Mucho calor, humedad, muebles rotos, paredes grises, un dolor de muelas, ya se hizo tarde para la cita, uno está viejo, lo asuelan las preocupaciones, y hay afuera un ruido infame que no se calla, son, por ejemplo, los contornos de un respetable mal humor. (Fernández Christlieb, 1999:74).

Con lo que se puede constatar también que forma y contenido no son dos cosas distintas: el material de la forma está dado por la forma misma: "La misma forma en otro material es otra, así que, por muy bien manufacturadas que estén las flores de plástico, siguen siendo flores-de-plástico y no flores". MerleauPonty trató al mismísimo lenguaje como forma dependiente de su contenido más carnal, esto es, su sonido: los fonemas como formas originarias de su significado (op. cit., p. 85).

\section{Del sentimiento a la imagen: la irrupción de lo femenino}

Una forma-sentimiento, o conjunto de formas, que aquí nos interesa es la de lo femenino. Georg Simmel abogó en su célebre ensayo Cultura femenina por mantener la dualidad masculino-femenino como dos tipos vitales y autónomos. Lo femenino, por su parte, sería un juego de formas con sus propias reglas. A la luz de los desarrollos teóricos feministas definir lo femenino resulta problemático puesto que cultura femenina, desde Simmel, es aquello que la cultura masculina ha sometido y excluido, a pesar de lo cual emerge como un contrapoder a la cultura hegemónica, es decir, como fuerza que contiene, limita y constriñe la colectividad. Lo femenino consiste en recuperar la tradición, la condición originaria de la colectividad que es, como dijera Hanna Arendt, la socialidad (Kristeva, 1999). En este sentido, lo femenino aparece como forma de la posmodernidad, como reivindicación del sentimiento y lo relacional (Lipovetsky, 1997). Lo cual no quiere decir que sean propiamente las mujeres quienes retomen la tarea de refundar la colectividad, en muchos casos ocurre al contrario: cada vez menos mujeres reconocen al amor como el todo.

Fue la razón ilustrada, atributo esencialmente viril, la que sirvió para dar a la mujer su emancipación racional con el argumento de la igualdad. Sin embargo la revolución romántica hará hincapié en la emoción y el sentimiento "femenino" como atributo fundamental del héroe masculino. De la gran dama 
capaz de igualar o superar a sus invitados poetas, filósofos o novelistas con su ingenio y raciocinio, pasamos al héroe afeminado. En la era romántica la mujer era idolatrada. Se escribe por amor, se muere por amor, se ama para morir. Todos los grandes principios se feminizan: la patria, la religión, la naturaleza, la vida y la muerte. Vale la pena morir por la bienamada mucho más que vivir por ella. Estas dos tradiciones antagónicas, la llustración y el romanticismo, confluyen y se acentúan con la posmodernidad (Gergen, 1991). Dicho de manera rudimentaria, mientras que las mujeres se masculinizan la cultura se feminiza.

Por otra parte, la refundación de lo relacional se pone de manifiesto con el reconocimiento de las prácticas sexuales de las mujeres y los homosexuales, hasta el grado de la institucionalización, lo que ha implicado otra paradoja característica de la posmodernidad: no la proclamación de una ruptura con el orden patriarcal sino una fuerte voluntad de integración, que es signo de una supuesta decadencia de los valores "tradicionales" de la familia, la escuela, la nación, la patria, y sobre todo la paternidad, el padre, la ley del padre, y por consiguiente la autoridad en todas sus formas (Roudinesco, 2004). El hecho de que familias formadas por homosexuales quieran reconocerse como una familia a nivel institucional (orden patriarcal) reafirma que las alternativas relacionales se aferran a las formas-sentimientos tradicionales.

La familia posmoderna aparece, según Roudinesco, en los años sesenta cuando aumentaron los divorcios, separaciones y recomposiciones conyugales. Esto es, a partir de la individualización de la mujer que accedía a su placer separándolo de la reproducción. Estas recomposiciones familiares han sido inspiración de relatos llevados a la ficción con un tratamiento "oscuro y maldito, de ahí que este espacio íntimo se haya convertido en una de las grandes experiencias subjetivas de nuestra época" (Roudinesco, 2004, p.10), con lo cual nos vamos acercando a la concepción contemporánea de lo melodramático, que podemos ver en el cine de Claude Chabrol, caso concreto de la película La flor del mal (2003) en que el incesto, el asesinato y la traición se concentran en el espacio íntimo de la familia, herencia de la tragedia griega.

\section{De Edipo a Narciso: de la tragedia al melodrama}

En un texto celebre de Marx que Eugenio Trías cita en su libro Lo Bello y Lo Siniestro, refiriéndose al arte griego, dice: "el problema no consiste en saber qué condiciones socioeconómicas determinaron el surgir del arte griego y en particular la tragedia griega, el problema es saber por qué este arte ha sido y sigue siendo pauta y modelo indiscutido, ¿A qué se debe este arraigo estético?" (Trías, 1985, p.125).

Freud se planteó el problema y osó afirmar que la metodología psicoanalítica podría responder al planteamiento marxista: la fuerza y la vigencia de la tragedia griega se debe a que puso al descubierto la estructura antropológica del inconsciente. La tragedia griega se compone de la presencia de un héroe, y conlleva a una catarsis: localización del héroe como idéntico a nosotros, a quien por un lado compadecemos y por el otro nos atemoriza. Se fantasea con realizar sus hazañas, es más, las realizamos junto con él, produciendo un sentimiento de horror por sus actos siniestros a través de los cuales se realiza el deseo en razón de la mediación escénica ficticia. La acción se produce en el orden de lo posible y no en el orden de lo factual. Este complejo de sentimientos produce en nuestras almas una catarsis que nos purifica o purga y finalmente llega la iluminación acerca de nuestra propia orientación del deseo. La literatura occidental muestra una sorprendente recurrencia a los temas 
edípicos, que reaparecen en aquellos momentos históricos en los que la familia humana se encuentra estructurada en formas que favorecen dichos traumas (Kaplan, 1982, p.51).

Sin embargo la identidad sexual posmoderna se acomoda más a las metamorfosis de Narciso que a la tragedia griega de Edipo (Roudinesco, 2004, p.132). Narciso es otro de los mitos fundacionales de la cultura occidental, que no se enamoró de sí mismo, como suele interpretarse, sino que quedó fascinado por la imagen reflejada en el agua sin reconocerla como suya. Es así que fue castigado por haber rechazado la mediación de otro en la construcción de su yo y haberse contentado con un simulacro: la autorreferencialidad, claro síntoma de locura. De manera que Narciso (narkosis) fue el fundador de la perversión iconofílica (Gubern, 2004, p.77).

Este antiedipismo funcionó para darle un viraje profundo a la sociedad. Se anunciaba el triunfo de lo múltiple sobre lo uno y del desorden normalizado sobre la simbolización trágica: una cultura del narcisismo y el individualismo, una religión del yo, una inquietud del instante, una abolición fantasmática del conflicto y la historia. A diferencia de Edipo, que se castiga para que la ciudad viva, Narciso se repliega en un encierro trágico pero protector (Roudinesco, 2004:175).

La subjetividad posmoderna, que hace hincapié en un mundo no lineal sino ramificado de incertidumbre, ansiedad y ambivalencia política, sirve para poner énfasis en la relatividad e incluso incompatibilidad de los puntos de vista y en la ambigüedad de las experiencias (Nichols, 1997, p.206). Las cuestiones de subjetividad, identificación y género se han convertido en el punto clave del debate de la ficción narrativa, que han afectado también a la estructura del cine melodramático.

La fragmentación narrativa del cine actual es consecuencia directa de la fragmentación del sujeto heredada del ideario posmoderno, en el que se vuelven preeminentes el eclecticismo, la heterogeneidad de los estilos en el seno de una misma obra, lo decorativo, lo metafórico, lo lúdico, lo vernacular, la memoria histórica. "Algunas películas experimentales se salen de la narración-representación para caer en la discontinuidad por la discontinuidad, en el extremismo de los planos-secuencia donde todo permanece inmóvil, en la experimentación no como investigación sino como procedimiento" (Lipovetsky, 1986, p.120).

\section{El realismo fílmico: del romanticismo a la posmodernidad}

El género [narrativo] no es más que un instrumento discursivo de control social, cuyo objetivo es apuntalar la ideología dominante. Aunque sea por la vía de desideologización. El melodrama es en sí mismo una ideología.

Pablo Pérez Rubio

Según Metz (2000/1963) los temas fílmicos se dividen en realistas e irrealistas, pero el poder de realización del vehículo fílmico es el denominador común de ambos, "asegurándole al primero su intensa familiaridad, tan reconfortante para la afectividad, y al segundo su potencial de extrañamiento, tan suculento para la imaginación" (p.33). 
El actual auge del documental apuesta de un modo u otro, por el punto de partida individual. Incluso las películas que aparentan abordar temas generales acaban centrándose en individualidades". (Losilla en Selva y Solà, 2002, p.127)

El hecho de filmar la vida cotidiana, ya sea sus protagonistas o sus decorados es un intento de fijarla, de convertir en una narración coherente los restos del naufragio de la contemporaneidad. El paso de la ficción a la realidad y viceversa es casi inapreciable.

La impresión de realidad que puede proporcionarnos un filme no se debe a una fuerte presencia del actor, como ocurre en el teatro, sino por el contrario, al débil grado de existencia de estas criaturas fantasmáticas que se agitan sobre la pantalla y que por lo tanto es más fácil que las invistamos con una realidad que surge de nosotros, proyecciones e identificaciones que se mezclan con nuestra percepción del filme. "Si el espectáculo cinematográfico ofrece una intensa impresión de realidad, es porque corresponde a un vacío en el cual el sueño se sumerge sin trabas" (Metz,2000/1963, p.37).

De aquí la importancia de las representaciones de lo femenino como algo auténticamente real en las ficciones como el melodrama, género fílmico por excelencia ginocéntrico. La crítica fílmica feminista afirma que el realismo como estilo no puede cambiar la conciencia porque no se aparta de las formas que encarnan la vieja conciencia, sólo refuerza estereotipos.

El aparato cinematográfico, enseñó a los espectadores a ocupar posiciones pasivas y de tendencias masculinas en relación con historias en las que se presentaban hombres activos y mujeres deseables. El realismo aportó el eje para esta operación, dirigiendo nuestra atención más allá de la enunciación y su ideología de contención, más allá de la escena y su autonomía imaginaría similar a la vida misma (Nichols, 1997, p.229).

Camilla Paglia ha señalado cómo en Francia el Romanticismo "zarandeado por los acontecimientos políticos, no tardó en transformarse en Decadentismo". Para entonces existía una literatura popular y de consumo que exigía rapidez, emoción y sentimientos básicos, pero las condiciones económicas, culturales y políticas de la época cambiaron la forma tradicional del texto que se inclinó a hacia un

exceso desbordante en el que se mezclan el melodrama exacerbado y la ironía autoparódica, evidenciando estrategias casi posmodernistas en cuanto a deconstrucción de la propia naturaleza del discurso narrativo. Es el fin de la "autenticidad" de los sentimientos y emociones como virtud romántica que irá dando paso a una nueva virtud moderna: el "artificio" (Palacios en Domínguez, 2006, p.139).

El profeta romántico sólo tiene sentido cuando es crucificado, si pierde su identidad individual para convertirse en símbolo doliente del destino humano. Por el contrario el pos-romántico propicia los excesos más salvajes siempre que tenga una justificación íntima para encontrarse a sí mismo y no para disolverse. "Profeta del artificio, del cinismo" (Palacios en Domínguez, 2006, p.149). He aquí uno de los antecedentes del melodrama contemporáneo.

El melodrama es un sistema narrativo que pone en escena experiencias emocionales a las que intenta dotar de sentido, apareciendo como un camino para la comprensión del mundo y de los conflictos humanos. (Pérez Rubio, 2004, p.32). Como forma utiliza las relaciones edípicas: las relaciones amorosas ilícitas (abiertas o incipientemente incestuosas), las relaciones entre madre e hijo, las relaciones entre 
esposos, las relaciones entre padre e hijo. Sin embargo en géneros fílmicos como los gángsteres o las películas del oeste, las mujeres quedan excluidas como protagonistas o de la narración completa.

El cine melodramático recuerda a la espectadora la fugacidad de la vida, la presencia constante del dolor físico y emocional, la amenaza permanente de la muerte, la imposibilidad de satisfacer los deseos y de dar soltura a las pasiones individuales más ocultas y la lucha por huir de los designios del destino (Pérez Rubio, 2004, p.43). El cine melodramático como el de terror se articula en torno al dolor como motor de tales estructuras narrativas. Como la muerte, el dolor es democrático, una experiencia al alcance de todos.

Los elementos que identifican al melodrama podrían ser los siguientes:

1. Estimulación del aspecto visual en detrimento de la palabra.

2. Los héroes se destacan más por sus carencias que por sus atributos.

3. Eros vinculado dramáticamente a Cronos y Tánatos: el amor en contra del tiempo y que súbitamente termina con la muerte.

4. Idea ilusoria de que el amor iguala a los seres humanos y rompe las jerarquías sociales.

5. Una herida o caída moral por motivos siempre ajenos al individuo.

6. La inadaptación dentro de la colectividad, marginación por ser diferente.

7. Está basado en la crisis emocional por la represión individual de los deseos y la voluntad de dejarse arrastrar por ellos; esta tensión es el hilo narrativo que sustenta el género.

8. Un camino lleno de pruebas en el que el héroe sobrevive manteniendo la fe en sí mismo, y como recompensa por su afán de superación, dando paso a la anagnórisis que posibilita el triunfo social y la aceptación de la comunidad. (Pérez Rubio, 2004).

Por otra parte, el melodrama oculta una doble falacia ideológica, en cuanto pretende esconder al espectador popular que esta supuesta democratización de los sentimientos o del dolor apuntala en realidad, al poder patriarcal y al orden social pequeño burgués.

En el siglo XX se amplifica y acelera el proceso populizador del melo: radionovelas, fotonovelas, relatos de quiosco (estilo Corín Tellado, la segunda escritora española más leída siguiendo de Miguel de Cervantes), telenovelas, revistas del corazón (que venden el melodrama cotidiano de personajes públicos), talk shows (dramas personales de carácter real), Gran Hermano, programas de reencuentros familiares, los anuncios publicitarios televisivos navideños trabajados con motivos emocionales, etc. Respiramos melodrama. En suma, lo melodramático constituye el mayor sistema de expresión de nuestro tiempo (Pérez Rubio, 2004, p.123).

El melodrama facilita la apertura y expresividad de las ideas que circulan en torno a la ficción manteniendo un alto nivel de operatividad para reformular constantemente espacios narrativos. La pluralidad de propuestas también tiene que ver con una fragmentación de las protagonistas que 
comparten espacio con otras versiones de los hechos. Por otro lado, esta irrupción de protagonistas femeninas construidas desde diferentes puntos de vista, no sólo desde el ojo hegemónico, renueva la fórmula del melodrama como da ejemplo el cine de Almodóvar (Días y Cerdán en Selva y Solá, 2002, p.85). El espacio donde se desarrolla el discurso melodramático es el Hogar, lo íntimo, de ahí que en estos espacios de costumbrismo se concrete mejor la apuesta de establecer líneas de desahogo para reajustar la sociedad.

\section{Representación del dolor: del cine clásico a la inexpresividad}

El dolor es el medio más directo para rasgar la pantalla de lo real, para mostrar las vísceras auténticas de la creación. Francisco González

El dolor en el cine clásico solía representarse, por ejemplo, con un violonchelo que acompaña a los personajes en la penosa travesía, con tempestades que derrumban objetos, con los insignificantes objetos cotidianos que reabren las heridas, como la bola de cristal en manos del Ciudadano Kane en el lecho de muerte. "Parecería que la representación melodramática no es más que un síntoma de la ansiedad ante la imposibilidad de transmitir el dolor individual, el deseo desesperado de convertirlo en algo universalmente comprensible y compartido" (Cueto en Domínguez, 2006, p.40). El melodrama despliega con el dolor su pensamiento más "imágico", afectivo, y su rompimiento radical con la lógica lingüística: hacer innecesarias las palabras para contagiar-transmitir los sentimientos.

El dolor en el cine melodramático actual se vislumbra, más bien por defecto, por la ausencia de movimiento y objetivo. Un sufrimiento contemporáneo se expresa ya por la negación de los códigos del cine clásico. Es como si el hombre moderno ya no confiara en la comunidad ni en el rito como forma de expresión de su dolor y prefiriera ocultarlo tras la carencia de expresión, la inmovilidad y el silencio. "La representación de la realidad se convierte en una especie de apoteosis del fragmento de la escisión, cuya imposibilidad de trascender a algo más es la metáfora perfecta de una determinada impotencia narrativa" (Losilla en Selva y Solà, 2002, p.125).

El cine comercial hollywoodense, abundante en formas melodramáticas, ha atemperado en cierta manera los excesos de su era clásica, pero sólo para asegurar la pervivencia de sus códigos adaptándolos a las sensibilidades y modas contemporáneas. El cine de Wong Kar Wai es auténtico icono de un dolor contemporáneo

que se retrae que se enrosca en lo más intimo, se hace críptico e inalcanzable [...] Rostros impasibles o de gestualidad reducida a la mínima expresión, cuerpos concentrados en gestos nimios, miradas impenetrables que ponen una barrera a cualquier posible intromisión en su mente. Una especie de agobiante hipertrofia del plano vacío (Cueto en Domínguez, 2006, p.47).

La sensibilidad artística occidental muestra una orientación definida hacia la conquista del placer estético de territorios inhóspitos y desasosegantes: su "progreso" se mide por la capacidad que tiene de mutar en placer lo doloroso y en conceder a esa mutación el concepto estético adecuado (Trías, 1985, p.162). 
La inscripción de las experiencias inconscientes reprimidas en la sensibilidad, daría lugar al sentimiento de lo siniestro, ese retorno de cosas que fueron familiares y cuya aparición ante el sujeto produce en él sentimientos de horror y de espanto. La categoría de lo siniestro ganaría esas experiencias para la sensibilidad y para la reflexión estética (Trías, 1985, p.170).

Las narrativas contemporáneas se nutren de la combinación extrema de elementos aparentemente opuestos: sadismo/masoquismo, placer/dolor, naturismo/romanticismo, humor/terror, razón/locura, Eros/ Tanatos, populismo/intelectualismo, emoción/artificio, etc. Es por ello que en la actualidad asistimos a una notable operación cultural consistente en un fértil reciclado de lo melodramático trenzado con la acumulación desordenada y la fragmentariedad propias del relato postmoderno; una integración que se fundamenta en el remake, la cita, la mixtificación y el homenaje reflejados no sólo en la configuración de personajes y situaciones-cliché, sino también en la utilización de la música, la planificación y el color (Pérez Rubio, 2004, p.142). Por tanto (como causa, o como consecuencia, no lo sabemos) nos encontramos en un período en el que "la fabricación de mitos sólo puede ser personal e individual", puesto que carecemos de "un valor trascendente claro con el que tengamos que reconciliarnos" (Kaplan, 1983, p.53).

\section{Epílogo: 21 gramos de cultura posmoderna}

En 1907 el doctor Duncan McDougall intentó determinar las características físicas del alma humana. Su procedimiento consistió en obtener el peso de varios sujetos poco antes de su muerte e inmediatamente después de ella. Comprobó que durante el proceso del colapso el peso disminuía sistemáticamente en todos los casos en aproximadamente veintiún gramos. La conclusión del doctor McDougall es representativa de la transición cultural que llevó del romanticismo al modernismo (Gergen,1991). El mundo occidental ha heredado del siglo XIX una visión romántica del yo que atribuye a cada individuo rasgos de personalidad: alma, sentimientos, creatividad. En el siglo XX, en cambio, la ciencia quiso responder el desafío del oráculo de Delfos "conócete a ti mismo", reto del que intentó ocuparse la psicología. El yo de un sujeto podía ser efectivamente conocido a través del método científico, ya que la ciencia enseña que el ser humano, al igual que el mundo, se compone de entidades fijas y reconocibles. La conclusión de McDougall es entonces que, por un lado, los seres humanos tenemos un alma que se desprende del cuerpo al morir, lo cual es una de las ideas románticas sobre nuestra esencia, y por otro lado, que el alma puede medirse a través de técnicas de experimentación, lo cual constituye uno de los tópicos de la ciencia moderna.

Es este elemento romántico-moderno de la determinación del peso del alma humana que da título a la película del cineasta mexicano Alejandro González Iñárritu, la cual parece ser icónica de eso que Gergen y otro gran número de pensadores llaman hoy día posmodernidad, que refiere entre otras cosas a la muerte de las verdades absolutas (científicas, religiosas, de sentido común) que tanto sentido dieron a las sociedades occidentales del milenio pasado. Para muchos científicos y filósofos el conocimiento que poseemos no puede ser ya pensado como representación de la realidad. El relativismo se infiltra en todos los aspectos de la vida. La realidad es una creación humana, relativa a cada comunidad, a cada cultura, y está constituida por su interpretación. Todo tipo de autoridad es cuestionada, no hay verdad más verdadera que otra. Así, eso que considerábamos nuestro yo se queda sin referentes absolutos, 
hemos perdido el piso. Para Gergen, el yo se encuentra determinándose por la multiplicidad de relaciones que vamos entablando momento a momento. Todo carece de lógica y sentido lineales.

Es así que en la cinta $\mathbf{2 1}$ gramos encontramos a Paul Rivers (Sean Penn), un hombre que después de ser sometido a cirugía de transplante, puede tener literalmente su corazón en la mano, mirarlo mientras sigue respirando, diferenciarlo del resto de él mismo y echarle la culpa de sus males. Paradójicamente, ahora que le ha sido trasplantado el corazón de otra persona quiere saber quién es ¿De qué depende su yo? ¿Qué tiene que ver con él el hombre que poseía ese corazón? Siente su identidad del todo trastocada, al grado de dejar atrás sus relaciones sentimentales para encontrarse con las de ese hombre que involuntariamente le cedió el corazón. Anteriormente su novia, decide que quiere embarazarse de él aunque esté por morir. Los padres ya no son necesarios.

Jack Jordan (Benicio del Toro) después de haber sido delincuente y drogadicto es capaz de convertirse de manera radical a un credo cristiano, y al poco tiempo cuestionarlo angustiosamente debido a las crueles circunstancias. Cristina Peck (Naomi Watts) acaba de perder a su esposo y a los pocos meses puede enamorarse de aquél que se quedó con su corazón. Una atmósfera en la que pueden convivir los torpes intentos de suicidio con la esperanza y la redención. Tres personajes que ven transformada su vida de un momento a otro en una historia que está contada más por la lógica de las sensaciones y los sentimientos y no del tiempo, pues las escenas brincan de lo que ya sucedió a lo que está por suceder sin que eso afecte la trama. Por cierto que el guionista, Guillermo Arriaga, atribuye esta manera de narrar sus historias (también escribió Amores Perros) a que tiene el famoso Trastorno por Déficit de Atención con Hiperactividad. Es la manera posmoderna de hacer cine y de vivir la vida. Los personajes podrán colapsarse en situaciones por demás trascendentes, para después no tener por qué volver a verse.

No está de más comentar que 21 gramos es una cinta rodada en Tennesse y Nuevo México, narrada en el contexto de una sociedad norteamericana, pero inicialmente pensada para la mexicana. Dirigida y escrita por mexicanos, actuada por un norteamericano nacido en Puerto Rico y una australiana nacida en Inglaterra. Diseño de arte por una alemana radicada en México y la música compuesta por un argentino.

\section{Referencias}

Domínguez, Vicente (Ed.) (2006). El dolor. Los nervios culturales del sufrimiento. Ensayos de cine, filosofía y literatura. Gijón: Festival Internacional de Cine de Gijón/EdiUNo.

Fernández Christlieb, Pablo (1999). La afectividad colectiva. México D.F.: Taurus.

Fernández Christlieb, Pablo (2004). La sociedad mental. Barcelona: Anthropos.

Fernández Christlieb, Pablo (2005). La velocidad de las bicicletas y otros ensayos de cultura cotidiana. México D.F.: Vila.

Gergen, Kenneth. (1991). El yo saturado. Dilemas de identidad en el mundo contemporáneo. Barcelona: Paidós, 1997.

Gubern, Romà (2004). Patologías de la imagen. Barcelona: Anagrama 
Kaplan, Ann E. (1982). Las mujeres y el cine. A ambos lados de la cámara. València: Ediciones Cátedra/ Universitat de València/Instituto de la Mujer.

Kristeva, Julia (1999). El genio femenino. 1. Hanna Arendt. Barcelona: Paidós.

Lipovetski, Gilles (1986). La era del vacío. Ensayos sobre el individualismo contemporáneo. Barcelona: Anagrama.

Lipovetski, Gilles (1997). La tercera mujer. Barcelona: Anagrama, 1999.

Marquard, Odo (1986). Apología de lo contingente. València: Institució Alfons el Magnànim, 2000.

Merleau-Ponty, Maurice (1951). La prosa del mundo. Madrid: Taurus, 1971.

Metz, Christian (2000). Ensayos sobre la significación en el cine (1964-1968). Barcelona: Paidós.

Nichols, Bill (1997). La representación de la realidad. Barcelona: Paidós.

Pérez Rubio, Pablo (2004). El cine melodramático. Barcelona: Paidós.

Roudinesco, Elisabeth (2004). La familia en desorden. Barcelona: Anagrama.

Selva, Martha y Solà, Anna (2002). Diez años de la muestra Internacional de Cine de Mujeres de Barcelona. Barcelona: Paidós.

Trías, Eugenio (1985). Lo bello y lo siniestro. Barcelona: Seix Barral.

\section{Formato de citación}

Robledo, Héctor. y Cano, Lirba. (2008). Narrativas de la posmodernidad. Del sentimiento como forma a la imagen melodramática. Athenea Digital, 15, 169-179 Disponible en http://psicologiasocial.uab.es/athenea/index.php/atheneaDigital/article/view/564

\begin{tabular}{l}
\hline Este texto está protegido por una licencia creative Commons. \\
Usted es libre de copiar, distribuir y comunicar públicamente la obra bajo las siguientes condiciones: \\
Reconocimiento: Debe reconocer y citar al autor original. \\
No comercial. No puede utilizar esta obra para fines comerciales. \\
Sin obras derivadas. No se puede alterar, transformar, o generar una obra derivada a partir de esta obra. \\
Resumen de licencia - Texto completo de la licencia
\end{tabular}

